\title{
Association Of Handgrip Strength With Body Mass Index Among Nigerian Students.
}

\author{
*Ibegbu Augustine Oseloka; Baita Muhammad Bello; Hamman Wilson Oliver; \\ Umana Uduak, Emmanuel; Musa Sunday Abraham \\ Department of Human Anatomy, Faculty of Medicine, Ahmadu Bello University Zaria-Kaduna State-Nigeria
}

\begin{abstract}
The aim of the present research was to study the relationship between handgrip strength with body mass index in 400 randomly selected Secondary School Students in Kano metropolis, Nigeria. The students were

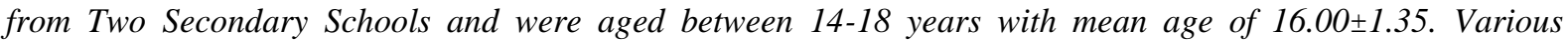
anthropometric variables studied include, the height, weight, BMI, hand width and length, upper and lower arm length, mid upper arm circumference (MUAC) and handgrip strength were measured using standard anthropometric measurement techniques. The results show that male students had higher mean values in height $(16.00 \pm 1.35 \mathrm{~kg})$, weight $(46.34 \pm 8.30 \mathrm{~cm})$, hand length $(19.34 \pm 0.98 \mathrm{~cm})$, hand width $(10.45 \pm 0.90 \mathrm{~cm})$, forearm length $(27.93 \pm 1.92 \mathrm{~cm})$, arm length $(31.93 \pm 2.46 \mathrm{~cm})$ and handgrip strength $(35.63 \pm 17.17)$, while having lower mean values in BMI $(17.45 \pm 2.30)$ and MUAC $(24.23 \pm 2.26 \mathrm{~cm})$. Male students had a higher mean handgrip strength which is significantly correlated $(P \leq 0.01)$ with all the variables studied while female students had handgrip strength with a significant positive correlation $(P \leq 0.01)$ with some of the variables. It may be concluded that handgrip strength had strong positive correlations with all the anthropometric variables associated with BMI in Nigerian Secondary School Students of Kano metropolis.
\end{abstract}

Keywords: Hand grip; BMI, Anthropometric Variables; Weight; Height; Hand; Students; Kano

\section{INTRODUCTION}

Hand grip strength is a physiological variable that is affected by a number of factors including age, gender and body size among others (Bassey and Harries, 1993; Baskaran et al., 2010). The estimation of hand grip strength is of immense importance in determining the efficacy of different treatment strategies of the hand and also in the hand rehabilitation (Benefice and Malina,1996) ). The power of hand grip is the result of forceful flexion of all finger joints with the maximum voluntary force that the subject is able to exert under normal biokinetic conditions (Charles and Burchfiel, 2006; Baskaran et al., 2010). Evidence has shown that there were strong correlations between grip strength and various anthropometric traits, such as weight, height, hand length and BMI as had been reported earlier by Ross and Rosblad (2002); Shyamal and Satinder (2011). In fact, the grip strength has been reported to be higher in dominant hand with right handed subjects, but there were no such significant differences between sides could be documented for left handed people (Incel et al., 2006). Right and left hand grip strengths were positively correlated with weight, height and body surface area in Indian population (Chatterjee and Chaudhuri, 1991).

The human hand is unique in being free of habitual locomotion duty and devoted entirely to functions of manipulation (Fess, 1992). Its effectiveness in these activities is due to particular configuration of the bones and muscles which permits opposition of the pulp surface of the thumb to the corresponding surfaces of the other four finger tips in a firm grasp, together with a highly elaborated nervous control and sensitivity of the fingers (Dixon et al., 2005). The hand length and body height ratio, the shape index which determines hand shape, the digit index which determines grasping capability and the palmar length/width ratio which determines palmar type without the digits, and other anthropometric parameters are all important parameters to be considered when studying the grip strength in any population of interest as they all play roles in grip strength (Mathiowetz et al., 1986; McArdle et al., 2001).

In the study of the relationships of hand grip strength with stature, weight, arm and calf circumferences and various subcutaneous skin folds, it was found that males attained greater values for those anthropometric variables and also have greater hand grip strength values than their female counterparts (Benefice and Malina, 1996; Naeem et al., 2008). It has been shown that there was age dependent increase in hand grip strength in boys and girls as well as the inter-gender differences was strongly associated with changes of fat free mass during the childhood (Sartorio et al., 2002; Nicola et al., 2006; Prakash et al., 2011).

Handgrip strength (HGS) is a measure of strength of several muscles in the hand and the forearm (Bassey and Harrie, 1991; Shyamal and Arvinder 2010). Hand grip strength is usually measured in either kilograms or Newtons depending on calibrations by squeezing a handgrip strength dynamometer with one's maximum strength. The power of grip is the result of forceful flexion of all finger joints with a maximal voluntary force that the subject is able to exert under normal biokinetic conditions (Navdeep and Shyamal, 2010). Hand grip 
strength can be quantified by measuring the amount of static force that the hand can squeeze around a dynamometer. The force has most commonly been measured in kilograms and pounds, but also in millilitres of mercury and in Newtons (Newman et al., 1984; Snih et al., 2002).

Hand grip strength is a reliable measurement when standardised methods and calibrated equipment are used, even when there are different assessors or different brands of dynamometers (Mathiowetz, 2002; Amit, 2006). There are different methods of positioning patients during measurement, and for calculating their grip strength from repeated measures, so the American Society for Surgery of the Hand and the American Society of Hand Therapists have standardized positioning, instruction and calculation of grip strength (Fess, 1992; Amit, 2006; Prakash et al., 2011).

Hand grip strength is found to be a significant determinant of bone mineral content and bone area at the forearm sites and has a positive correlation with lean body mass and physical activity and determines the muscular strength of an individual (Foo, 2007; Baskaran, et al., 200). Hip and waist circumferences measurement are good markers of fat mass, bone mineral content and lean mass are strongly correlated with maximum isometric grip force (Rasid and Ahmed, 2006; Prakash et al., 2011).

The assessment of hand grip strength assumes importance in a number of situations. It may be used in the investigation and follow-up of patients with neuromuscular diseases (Charles and Burchfiel, 2006; Foo, 2007). It is also of use as functional index of nutritional status and can predict the extent of complications following surgical intervention in hospitalized patients (Shyamal and Arvinder, 2010). The aim of the research was to study the association between hand grip strength and other anthropometries namely height, weight, BMI, hand length, hand width, forearm length, arm length, and MUAC among Secondary School Students in Kano Nigeria.

\section{Study Population}

\section{Materials And Method}

A total of four hundred Secondary School Students of 14-18 years of age were randomly selected for the study from two different Secondary Schools in Kano Municipality, Kano State Nigeria. The study samples were made up of two hundred Students from each of the Schools comprising of one hundred males and one hundred females each. The Schools are the Governor's College with 200 participating Students, made up of one hundred (100) Male students and one hundred (100) Female Students, and the First Grade Comprehensive School with 200 participating Students, made up of one hundred (100) Male students and one hundred (100) Female Students, making up the total of four hundred (400) Students.

\section{Study Area}

Kano State is located in North-Western Nigeria as part of former Northern Region and borders Katsina State to the north-west, Jigawa State to the north-east, Bauchi and Kaduna States to the south. It is indigenous to Hausa and Fulani tribes. Kano Environment refers to the administrative area known as Kano State. It is so called because the State capital is named Kano. The Kano environment covers an area extending between latitudes $12^{0}$ $40^{\prime}$ and $10^{\circ} 30^{\prime}$ and longitude $7^{\circ} 40^{\prime}$ and $9^{\circ} 30^{\prime}$.

The two Schools selected for the study are the Governor's College, along Ibrahim Taiwo road, Kano and First Grade Comprehensive School on Lawal Dambazau link, Kano. All the participants were Hausas from Kano State.

\section{Measurements and Data Collection}

Body weights were measured using a standard scale with light clothing on, without any footwear. Heights were measured with each subject in upright position in front of a wall looking ahead and heels touching one another. BMI of the Participants were calculated using the measurements of the weight in kilograms divided by the square of the height in meters $(\mathrm{kg} / \mathrm{m} 2)$. The hand lengths were measured using standard measuring tape in each subjects, defined as the distance between the mid-point of the distal wrist crease and the tip of the middle finger.

Mid Upper Arm Circumference (MUAC), is the circumference of the upper arm measured at the midpoint between the tip of the shoulder and the tip of the elbow, at the olecranon process and acromion.

Hand dynamometer made by Xinjing Sports, China, was used to measure the grip strength of the participants. Each participant was allowed to sit on a chair with the elbow flexed at 90 degrees and the forearm in semi pronation lying on an arm rest. The participants were asked to squeeze the dynamometer with their hand and the grip strengths were recorded.

\section{Statistical Analysis}

Standard descriptive statistics (mean \pm standard deviation) were determined for directly measured and derived variables. Pearson's correlation coefficients were used to establish the correlation of handgrip strength with other variables. A $\mathrm{P} \leq 0.05$ probability level was used to indicate significance.

\section{Results}


The result show that the mean values for the Age, height, weight, BMI, hand length, hand width, forearm length, hand width, forearm length, arm length, MUAC and handgrip strength (HGS) in the general population sample are as shown in Table 1 .

The descriptive statistics in both male and female students in each case showing the mean \pm S.D., minimum and maximum values for each variable are as shown in Table 2. All the anthropometric variables studied were correlated to Handgrip strength and also to each other to test for any relationship between the parameters as shown in Table 3. The results showed a positive correlation between handgrip strength and the anthropometric variables studied. While Tables 4 and 5 show the correlation matrix between the anthropometric variables and HGS in males and females respectively. The regression equations for HGS according to age are presented in Table 6.

Table 1: Descriptive Statistics for general samples $(\mathrm{N}=400)$

\begin{tabular}{|l|c|c}
\hline \hline Parameters & Mean \pm S.D. & Min-Max \\
\hline Age & $16.00 \pm 1.35$ & $14-18$ \\
\hline HT(m) & $1.60 \pm 0.076$ & $1.39-1.83$ \\
\hline WT $(\mathrm{kg})$ & $46.34 \pm 8.30$ & $22.00-89.00$ \\
\hline BMI $\left(\mathbf{k g} / \mathbf{m}^{2}\right)$ & $18.02 \pm 2.81$ & $9.40-30.10$ \\
\hline HL $(\mathbf{c m})$ & $19.34 \pm 0.98$ & $16.50-22.00$ \\
\hline HW $(\mathbf{c m})$ & $10.45 \pm 0.90$ & $8.50-12.00$ \\
\hline FAL $(\mathbf{c m})$ & $27.93 \pm 1.92$ & $24.00-39.00$ \\
\hline AL $(\mathbf{c m})$ & $31.93 \pm 2.46$ & $21.00-38.00$ \\
\hline MUAC $(\mathbf{c m})$ & $24.37 \pm 2.27$ & $19.00-32.00$ \\
\hline HGS $(\mathbf{N})$ & $35.63 \pm 17.17$ & $10.00-102.00$ \\
\hline \hline
\end{tabular}

$\mathrm{N}=$ total number, HT= Height, WT = Weight, BMI = Body Mass Index, HL = Hand length, HW = Hand Width, $\mathrm{FAL}=$ Forearm Length, AL $=$ Arm Length, MUAC $=$ Mid Upper Arm Circumference, HGS $=$ Hand Grip Strength.

Table 2: Descriptive Statistics for male and female samples

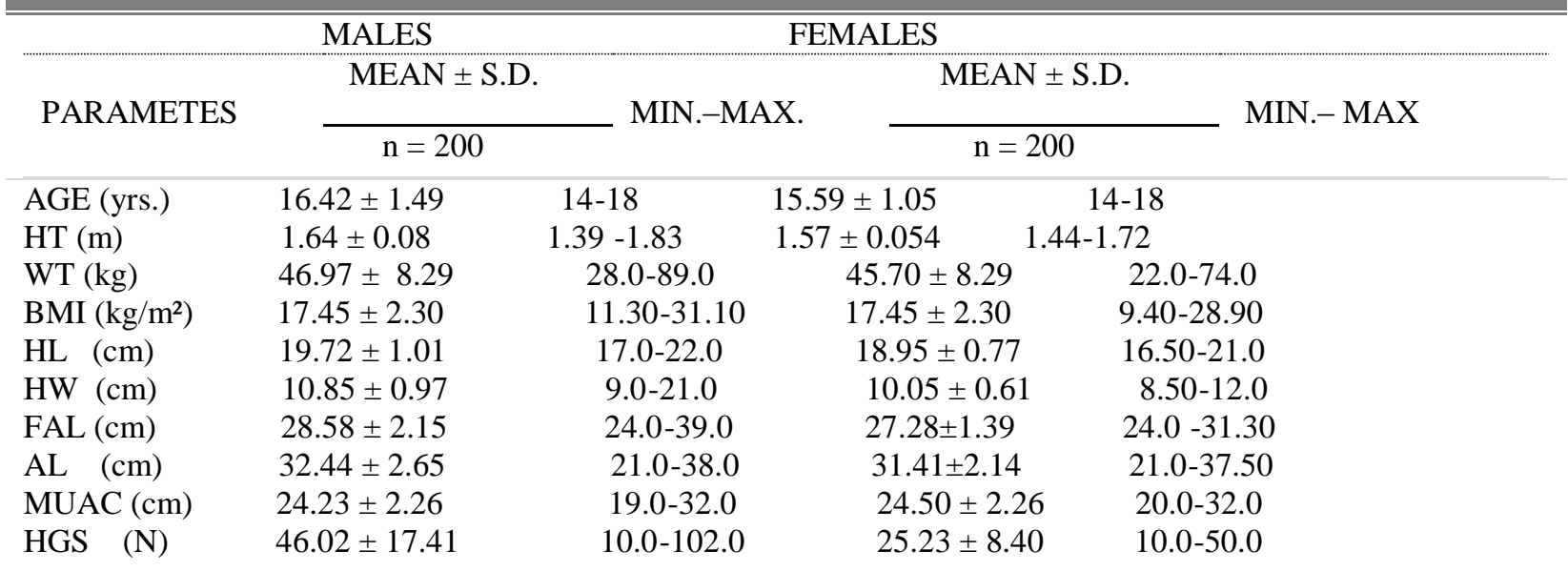

$\mathrm{n}=$ total number, HT = Height, WT = Weight, BMI = Body Mass Index, HL = Hand length, HW = Hand Width, $\mathrm{FAL}=$ Forearm Length, AL = Arm Length, MUAC = Mid Upper Arm Circumference, HGS = Hand Grip Strength. 
Table 3

Correlation betw een the variables in male and female samples

\begin{tabular}{|c|c|c|c|c|c|c|c|c|c|c|}
\hline & AGE & HT & WT & BMI & HL & HW & FAL & AL & MUAC & HGS \\
\hline AGE & 1 & & & & & & & & & \\
\hline HT & .431 & 1 & & & & & & & & \\
\hline WT & .331 & $.485^{* *}$ & 1 & & & & & & & \\
\hline BMI & $.116^{*}$ & -.045 & $.848^{* *}$ & 1 & & & & & & \\
\hline HL & .278 & $.646^{* *}$ & $398 * *$ & .073 & 1 & & & & & \\
\hline $\mathrm{HWV}$ & $.286^{* *}$ & $.417^{* *}$ & $.350^{* *}$ & $.146^{* *}$ & $.410^{* *}$ & 1 & & & & \\
\hline FAL & $.256^{* *}$ & $.631^{* *}$ & $317^{* *}$ & -.019 & $.562^{* *}$ & $.320^{* *}$ & 1 & & & \\
\hline$A L$ & $.278 * *$ & $.604^{* *}$ & $364^{* *}$ & .066 & $.481^{* *}$ & $.320^{* *}$ & $.485^{* *}$ & 1 & & \\
\hline MUAC & $.280^{* *}$ & $.180^{* *}$ & $.796^{* *}$ & $.807^{* *}$ & $.197^{* *}$ & $.293^{* *}$ & $.120^{*}$ & $208 * *$ & 1 & \\
\hline HGS & $307^{* *}$ & $.485^{* *}$ & $.237^{* *}$ & -.026 & $.357^{* *}$ & $320^{* *}$ & $.294^{* *}$ & $.295^{* *}$ & $.125^{*}$ & 1 \\
\hline $\begin{array}{r}* * \text { Corre } \\
* \text { Corre }\end{array}$ & $\begin{array}{l}\text { ation is s } \\
\text { ation is s }\end{array}$ & $\begin{array}{l}\text { nific ant } \\
\text { nific ant }\end{array}$ & $\begin{array}{l}0.011 \mathrm{ev} \\
0,051 \mathrm{ev}\end{array}$ & $\begin{array}{l}1(2 \text {-taile } \\
1 \text { (2-taile }\end{array}$ & & & $\mathrm{n}=400$ & & & \\
\hline
\end{tabular}

Table 4

Correlation betw een the variables in male samples

\begin{tabular}{lllllllll}
\hline AGE & HT & WT & BMI & HL & HW & FAL & AL & MUAC \\
\hline
\end{tabular}

\begin{tabular}{|c|c|c|c|c|c|c|c|c|c|c|}
\hline AGE & 1 & & & & & & & & & \\
\hline HT & $.439 * *$ & 1 & & & & & & & & \\
\hline WT & $.450^{k *}$ & $.650^{* *}$ & 1 & & & & & & & \\
\hline BMII & $.250^{k *}$ & $.163^{*}$ & $.851^{* 8}$ & 1 & & & & & & \\
\hline $\mathrm{HL}$ & $.291^{k *}$ & $.637^{* 8}$ & $.415 * 8$ & .111 & 1 & & & & & \\
\hline $\mathrm{HW}$ & $.245^{k *}$ & $.289 * *$ & $.413 * 8$ & $.359 * \approx$ & $.247^{* 8}$ & 1 & & & & \\
\hline FAL & $.235^{k *}$ & $.601^{* *}$ & $.378^{* 8}$ & .080 & $.512^{88}$ & $.178 *$ & 1 & & & \\
\hline AL & $.252^{* * *}$ & $.645^{* *}$ & $.404^{* *}$ & .100 & $.515^{* 8}$ & $.299 * *$ & $.501^{8 *}$ & 1 & & \\
\hline $\mathrm{MUAC}$ & $.459^{8 *} *$ & $.369 * *$ & $.799 * 8$ & $.798^{* 8}$ & $197^{* 8}$ & $.411^{* *}$ & $.191^{8 *}$ & $.262^{* *}$ & 1 & \\
\hline HGS & $.516^{k *}$ & $.430^{* *}$ & $.568^{* 8}$ & $.463^{* *}$ & $.341^{* 8}$ & $314^{* *}$ & $276^{* *}$ & $.334^{* *}$ & $\begin{array}{l}.626^{* *} \\
.000 \\
\end{array}$ & 1 \\
\hline $\begin{array}{l}* * \text { Correl } \\
* \text { Correl }\end{array}$ & $\begin{array}{l}\text { tion is } \mathrm{s} \\
\text { tion is } \mathrm{s}\end{array}$ & $\begin{array}{l}\text { gnificant } \\
\text { gnificant }\end{array}$ & $\begin{array}{l}0,011 \mathrm{lev} \\
0,05 \mathrm{lev}\end{array}$ & $\begin{array}{l}\text { (2-taile } \\
\text { (2-taile }\end{array}$ & & $\mathrm{n}=20$ & & & & \\
\hline
\end{tabular}


Table 5

Correlation matrix between the variables in female samples

\begin{tabular}{|c|c|c|c|c|c|c|c|c|c|c|}
\hline & AGE & HT & WT & BMI & HL & HW & FAL & $A L$ & MUAC & HGS \\
\hline AGE & 1 & & & & & & & & & \\
\hline HT & .45 & 1 & & & & & & & & \\
\hline WT & $.158 \%$ & $.323 * *$ & 1 & & & & & & & \\
\hline BMI & $.149^{\circ}$ & -.054 & $.926^{* *}$ & 1 & & & & & & \\
\hline HL & -.027 & $.441^{* *}$ & $394^{* *}$ & .243 & 1 & & & & & \\
\hline HWV & .029 & $.227^{* *}$ & $.281^{* *}$ & $205^{* *}$ & $367 * *$ & 1 & & & & \\
\hline FAL & -.079 & $.498 * *$ & $.224^{* *}$ & .032 & $.467 * *$ & $.263^{* *}$ & 1 & & & \\
\hline$A L$ & $.194^{* *}$ & $.479 * *$ & $.304^{* *}$ & .133 & $.328 * *$ & $.187^{* *}$ & $.359 * *$ & 1 & & \\
\hline MUAC & .104 & .048 & $.811^{* *}$ & $.840^{* *}$ & $.302^{* *}$ & $.296^{* 8}$ & .095 & $.186^{* *}$ & 1 & \\
\hline HGS & $.167 \%$ & $.172 *$ & $.162 *$ & .097 & $.151^{*}$ & .151 & $.208 * *$ & .061 & .124 & 1 \\
\hline
\end{tabular}

** Correlation is significant at 0.01 leve1 (2-tailed) $\quad \mathrm{n}=200$

* Correlation is significant at 0,05 level (2-tailed)

$\mathrm{HT}=$ Height, WT = Weight, $\mathrm{BMI}=$ BodyMass Index, $\mathrm{HL}=$ Hand Length, HW =

Hand Width, FAI $=$ Forearm Length, AL = Arm Length, MUAC = Mid Upper Arm

Circumference, HGS = Hand Grip Strength.

Table 6: Regression formulas for HGS according to age

\begin{tabular}{lccc}
\hline & AGE $(\mathrm{yrs})$ & MALE/AGE $(\mathrm{yrs})$ & FEMALE/AGE(yrs) \\
\hline HGS VS BMI & $\mathrm{y}=0.6073 \mathrm{x}+24.727$ & $\mathrm{y}=1.5847 \mathrm{x}+15.326$ & $\mathrm{y}=0.21 \mathrm{x}+23.818$ \\
HGS VS HL & $\mathrm{y}=7.9639 \mathrm{x}+118.3$ & $\mathrm{y}=7.798 \mathrm{x}-108.79$ & $\mathrm{y}=4.6463 \mathrm{x}-61.179$ \\
HGS VS HW & $\mathrm{y}=3.8076 \mathrm{x}-4.4072$ & $\mathrm{y}=2.2932 \mathrm{x}+18.922$ & $\mathrm{y}=6.2692 \mathrm{x}-36.358$ \\
HGS VS FAL & $\mathrm{y}=3.5877 \mathrm{x}-64.516$ & $\mathrm{y}=2.7611 \mathrm{x}-34.638$ & $\mathrm{y}=2.8184 \mathrm{x}-49.843$ \\
HGS VS AL & $\mathrm{y}=2.2822 \mathrm{x}-37.178$ & $\mathrm{y}=2.5403 \mathrm{x}-38.685$ & $\mathrm{y}=0.7198 \mathrm{x}+5.0105$ \\
HGS VS MUAC & $\mathrm{y}=2.3897 \mathrm{x}-22.542$ & $\mathrm{y}=3.8765 \mathrm{x}-51.663$ & $\mathrm{y}=0.5095 \mathrm{x}+15.336$ \\
HGS VS HT & $\mathrm{y}=120.66 \mathrm{x}-157.67$ & $\mathrm{y}=120.9 \mathrm{x}-153.25$ & $\mathrm{y}=54.448 \mathrm{x}-58.172$ \\
HGS VS WT & $\mathrm{y}=0.4373 \mathrm{x}+15.399$ & $\mathrm{y}=0.5081 \mathrm{x}+21.861$ & $\mathrm{y}=0.0132 \mathrm{x}+24.654$ \\
\hline
\end{tabular}

HT=Height, WT=Weight, BMI=Body Mass Index, HL=Hand Length, HW=Hand Width, FAL=Forearm Length, AL=Arm Length, MUAC=Mid Upper Arm Circumference, HGS= Hand Grip Strength. $y=$ dependant variable (HGS), $\mathrm{x}$ independent variable (age)

\section{Discussion}

The study of the Association between handgrip strength, BMI and other anthropometric parameters was undertaken in four hundred Nigerian Secondary School Students of ages 14 to 18 years in Kano metropolis. The study correlated BMI and other anthropometric traits with handgrip strength of Students. The results revealed strong positive correlations between age, height and weight with handgrip strength in both males and females. Sartorio et al (2002) had reported that the age dependent increase of hand grip strength in males and females were strongly associated with changes of muscle mass during the childhood. The results from the present study are consistent with previous researches demonstrating stronger grip for men than women within the same age strata, and that hand grip strength decreases with advancement in age (Chatterjee and Chowdhuri,1991; Bohannon et al., 2006; Charles and Burchfiel, 2006). 
The results showed that Male Students showed higher mean values for all the tested anthropometric variables than females, except for BMI and MUAC where females had higher mean values. Based on the present study, males also showed a higher mean value for Hand grip strength and this agrees with the study conducted by Shyamal and Sartinder (2011), which showed that males have a higher mean values of all the anthropometric parameters than females.

The present study has demonstrated that males are generally taller, heavier, and have longer hand length, hand width, forearm length, and arm length, with higher Hand grip Strength than their female counterparts. While females on the other hand, had higher BMI and MUAC than their male counterparts. This could either be as a result of females not involved in much physical activity as males do or due to higher fat deposition in females as compared to males. Also the existence of greater percentage of muscularity among male students than their female counterparts are may be because of the regular exercise of the males that prevented the accumulation of fat in the body (McArdle et al., 2001; Foo, 2007; Prakash et al., 2011). This is because, Sartorio et al. (2002) in their study had reported that age dependent increase of handgrip strength in boys and girls were strongly associated with changes of muscle mass during their childhood.

It was reported earlier that physical performance had a strong association with body strength, shape, size, form and structure of an individual (Ross and Rösblad 2002; Foo 2007). The findings of the present study follow the same direction highlighting a highly significant positive correlation between all the anthropometric variables measured and handgrip strength both in males and females.

It has been reported that as a rule, handgrip strength of both right and left hand dominant was stronger in males than females across all age groups (Newman et al. 1984; Mathiowetz et al. 1986; Naeem et al., 2008). The findings of the present study also followed the same direction in both male and female students. The Males have higher mean values in all the anthropometric variables than their female counterparts. It has been reported earlier that men possessed considerably greater strength than women for all muscle groups tested (McArdle et al. 2001; Bohannon et al., 2006; Shyamal and Satinder, 2011).

In the case of height, a positive correlation with the hand grip strength could be as a result of different factors such as higher heights that would lead to longer arms, with greater lever of arm for higher force generation thus, resulting in an efficient amount of force. Similarly, Chatterjee and Chowdhuri (1991) agreed that hand grip strength when measured by hand dynamometer was positively correlated with weight, height and body surface area.

When correlating HGS, in the general sample of males and females combined, with all the tested anthropometric variables, all the variables showed a strong positive correlation to Hand grip Strength. This was also shown to be true when the same correlation was made in male student samples only. But in female samples, however, the correlation only showed a positive relationship between Hand grip Strength and age, height, weight, hand length, forearm length while BMI, hand width, arm length, and MUAC showed no significant correlation. The regression formulae for predicting Hand grip strength were obtained according to age in males and females. and based on these findings, the present study was in agreement with the findings of the previous studies of Cagatay et al, (2011); Shyamal and Satinder (2011).

\section{Conclusion}

From the result of the present study, it could be concluded that the BMI and all the other tested anthropometric variables are positively correlated to Hand grip strength. It could also be concluded that male students are taller, heavier, have higher hand length, hand width, forearm length, and arm length than their female counterparts. This is because these variables are positively correlated to Handgrip strength, however, males showed a higher Handgrip strength than females.

\section{References}

[1] Amit B (2008). Body Composition and Hand Grip Strength in male Brick-field Workers. Malaysian journal of Medical Sciences.; 15(1): 31-36.

[2] Baskaran C, Arindam G, Chandan P, and Bidhan C (2010). Anthropometric traits predict Hand Grip Strength in Healthy Normal. Springer Journal of Hand \& Microsurgery 2(2):58 61.

[3] Bassey EJ, Harries UJ (1993). Normal values for hand grip strength in 920 men and women over 65 years, and longitudinal changes over 4 years in 620 survivors. Clinical Science; $15(1)$ : $331-337$.

[4] Benefice E, Malina R (1996). Body size, body composition and motor performances of mild-to-moderately undernourished Senegalese children. An Hum Biol, 23(4): 307-321.

[5] Bohannon RW, Peolsson A, Massy-Westropp N, Dastrosiers J, and Bear - Lehman J (2006). Reference values for adult Grip Strength measured with a Jamar dynamometer; a descriptive meta-analysis. Physiotherapy; 92: 11-15.

[6] Charles LE and Burchfiel CM (2006). Occupational and other risk factors for Hand Grip Strength. Environ Med.; 63:820-827.

[7] Chatterjee S, Chowdhuri BJ (1991). Comparison of grip strength and isometric endurance between right and left hands of men and their relationship with age and other physical parameters. J Hum Ergol, 20(1): 41-50.

[8] Dixon WG, Lunt M, Pye SR, Reeve J, Felsenberg D, Silman AJ, and O’Neill TW (2005). Low GSis associated with Bone mineral density and vertebral fracture in women. Rheumatology; 44(5):642 -646.

[9] Fess EE (1992). Clinical assessment recommendations. Casanova JS, editor. Chicago: American of Hand Society of Hand Therapist; Grip Strength: pp. $41-45$. 
[10] Foo LH (2007). Influence of body composition, muscle strength, diet and physical activity on total body and forearm bone mass in Chinese adolescent girls. Br J Nutr, 98(6): 1281-1287.

[11] Incel NA, Ceceli E, Durukan PB, Erdem HR, Yorgancioglu ZR (2002). Grip strength: Effect of hand dominance. Singapore Med J, 43(5): 234- 237

[12] Mathiowetz V, Kashman N, Volland G. Weber K, Dove M, and Rigers S (1986). Grip and Pinch Strength: Normative data for adults. Arch Physical Rehabilitation; 66 - 72. Mathiowetz (2002)

[13] McArdle WD, Katch FI, Katch VL (2001). Exercise Physiology: Energy, Nutrition, and Human Performance.5th Edition. Philadelphia: Lippincott Williams and Wilkins, pp. 506-507.

[14] Naeem A, James M, Jr, Stephen PH, Garry P, Allan G, James CW, Khalid A, Rana H, Karen MW, Stanley L, Alfred FC, Jr, and Clay BM (2008). Acquired Weakness, Hand Grip Strength, and Mortality in Critically Ill Patients; 178:261-268.

[15] Napdeep K and Shyamal K (2010). An association of Nutritional status and Hand Grip Strength In Female Laborers of North India. Anthropologist; 12(4): 237 - 243.

[16] Newman T, Hurbo J, Jurimae J (1984). Relationship of handgrip strength with anthropometric and body composition variables in prepubertal children. J Copmar Hum Biol; 60:225-38.

[17] Nicola M, Massy-Westropp, Catherine H (2006). Age and Gender Stratified Normative data in a population-based study. BioMed Central.; doi: 10.1186/1756-0500-4-127.

[18] Prakash C, Dhara PS, and Sujaya D (2011). Hand Grip Strength of Older Persons in Relation to Body Dimensions and Nutritional Status. Journal of the Indian Academy of Geriatrics; 7:143-149

[19] Rashid R and Ahmed SF (2006). Assessment of bone health and body composition in Glasgow school children. European Congress of Endocrinology. 11: P. 35.

[20] Ross CH, Rösblad B. (2002). Norms for grip strength in children aged 4-16 years. Acta Paediatrica, 91(6): 617-625.

[21] Sartorio A, Lafortuna CL, Pogliaghi S, Trecate L (2002). The impact of gender, body dimension and body composition on handgrip strength in healthy children. J Endocrinol Invest, 25(5): 431-435.

[22] Shyamal K and Arvinder PS (2010). Effect of Hand Dominance in Grip Strength in Colligiate Population-based Amritsar, Punjab, India. Anthropologist; 12(1): 13 - 16.

[23] Shyamal K, and Satinder PK. (2011). Colligiate of Hand Grip Strength in selected Hand-Arm-Anthropometric Variables in Indian Inter-University Female Volleyball players (2011). Asian journal of sports Medicine;2(4) : 220 - 226.

[24] Snih A, Markides S and Ray L. (2002). Hand Grip Strength and Mortality in Older Americans and Mexicans. J Am Geriatr Soc.;50:1250-1256. 